\title{
Potentially Life-Threatening Ictal Bradycardia in Intractable Epilepsy
}

\author{
Céline Odier, Dang Khoa Nguyen, Alain Bouthillier, Normand Giard, \\ Jean-Marc Saint-Hilaire, Patrick Cossette
}

\begin{abstract}
Background: Recently a high prevalence of asystole was found in individuals with refractory epilepsy. Objective: To measure the prevalence and characterize the pattern of ictal bradycardia (IB) in our cohort. Method: We analyzed ictal heart rate (HR) and seizure localization in 69 consecutive individuals with intractable epilepsy. Ictal bradycardia was defined by HR less than 60 beat per min (bpm) and a fall of more than $30 \mathrm{bpm}$. Results: Ictal bradycardia was observed in $1.9 \%$ of seizures and in five individuals $(7.2 \%)$, who presented IB in $5.7 \%$ of their seizures. Four of them had also relative IB (a decrease of HR of more than $10 \mathrm{bpm}$ ) in the majority of their seizures. Four additional individuals showed relative IB. Conclusion: Ictal bradycardia occurs more frequently than previously thought in individuals with refractory epilepsy. Recognition of individuals with small to moderate ictal HR decrease may help to identify those at greatest risk for asystole.
\end{abstract}

RÉSUMÉ: Bradycardie ictale mettant en danger la vie du patient atteint d'épilepsie réfractaire au traitement. Contexte : On a constaté récemment une prévalence élevée d'asystolie chez les patients atteints d'épilepsie réfractaire au traitement. Objectif : Le but de cette étude était de mesurer la prévalence et de caractériser la bradycardie ictale (BI) dans notre cohorte de patients. Méthodes : Nous avons analysé la fréquence cardiaque (FC) ictale et la localisation des crises chez 69 individus consécutifs atteints d'épilepsie réfractaire au traitement. La BI a été définie comme étant une FC de moins de 60 battements par minute (bpm) et une baisse de plus de $30 \mathrm{bpm}$. Résultats : Une BI a été notée au cours de 1,9\% des crises et chez 5 individus (7,2\%), qui présentaient une BI au cours de 5,7\% de leurs crises. Quatre d'entre eux avaient également une BI relative (une diminution de la FC de plus de $10 \mathrm{bpm}$ ) au cours de la majorité de leurs crises. Quatre autres individus présentaient une BI relative. Conclusion: La BI survient plus souvent qu'on ne le pensait chez les patients atteints d'épilepsie réfractaire au traitement. L'identification des patients qui présentent une diminution de la FC de légère à modérée pourrait aider à identifier ceux dont le risque d'asystolie est le plus élevé.

Can. J. Neurol. Sci. 2009; 36: 32-35

The incidence of sudden unexpected death in epilepsy (SUDEP) is up to $1 / 200$ patients-years in adults with refractory epilepsy ${ }^{1}$. Among the potential mechanisms underlying SUDEP, cardiac dysrhythmia and central apnoea have been proposed ${ }^{2}$. Various ictal arrhythmias have been described. The most frequent is tachycardia ${ }^{3,4}$. In turn, ictal bradycardia (IB) is generally believed to be rare ${ }^{2,4}$. The reported prevalence varies according to bradycardia definition ${ }^{2,4,5}$. However, in a recent prospective study of 19 individuals with intractable seizures, up to $21 \%$ exhibited severe bradycardia or asystole requiring permanent pacemaker $(\mathrm{PM})^{3}$. The incidence of bradycardia among all recorded seizures was approximately $2 \%$, suggesting that individuals exhibit severe IB in only a small percentage of their seizures ${ }^{3}$. In the present study, we intended to estimate the prevalence of IB in our population of intractable epilepsy, and determine the localization of the epileptic focus in the individuals with IB.

\section{METHOD}

We reviewed 383 consecutive investigations in our epilepsy monitoring unit (CHUM, Montreal, Canada) from January 2001 to September 2005. All individuals had prolonged video-EEG

\footnotetext{
From the Department of Medicine, Neurology Division, Montreal University Health Centre (CHUM), Montreal, Quebec, Canada.

Received April 24, 2008. Final Revisions Submitted July 3, 2008. Correspondence to: Patrick Cossette, CHUM-Hôpital Notre-Dame, 1560 Sherbrooke est, Montréal, Québec, H2L 4M1, Canada.
} 
Table: Relative severity of bradycardia events

\begin{tabular}{|c|c|c|c|c|c|c|}
\hline Individuals & Epileptic focus & $\begin{array}{c}\text { Relative bradycardia } \\
\text { decrease }>10 \mathrm{bpm}+ \\
\mathrm{HR}<=80\end{array}$ & $\begin{array}{c}\text { Absolute bradycardia } \\
\text { decrease }>30 \\
+ \text { HR } 42-60 \\
\end{array}$ & $\begin{array}{l}\text { Severe bradycardia } \\
\text { decrease }>30+\mathrm{HR} \\
<=42 \mathrm{bpm} \text { or } \mathrm{PM}^{*}\end{array}$ & $\begin{array}{l}\text { Asystole } \\
(>=3 \mathrm{sec})\end{array}$ & $\begin{array}{l}\text { Total of } \\
\text { seizures }\end{array}$ \\
\hline 1 & Frontal Right & 12 & 2 & & & 22 \\
\hline 2 & Frontal Left & 3 & 2 & $4 *$ & 4 & 16 \\
\hline 3 & Frontal Left & 18 (9 with HR =42) & 0 & 2 & & 25 \\
\hline 4 & Temporal Left & & 2 & 6 & 1 & 9 \\
\hline 5 & Parieto-occ Right & 43 & 1 & & & 67 \\
\hline 6 & Parietal right & $1(\min 54)$ & & & & 6 \\
\hline 7 & Temporal left & $3(\min 60)$ & & & & 4 \\
\hline 8 & Occipital left & $1(\min 60)$ & & & & 18 \\
\hline 9 & Parietal right & $1(\min 72)$ & & & & 9 \\
\hline
\end{tabular}

*Triggered Pacemaker, set at 50bpm

monitoring and magnetic resonance imaging (MRI). Most of them had subtraction ictal SPECT co-registered to MRI (SISCOM). The epileptic focus was considered clearly established if: 1) MRI disclosed a significant lesion, congruent with ictal EEG and/or SISCOM; or 2) MRI showed no lesion, but the seizure onset was clearly established based on ictal EEG and/or SISCOM. We excluded individuals with: 1) no history of intractable epilepsy; 2) no clear epileptic focus; 3) less than three seizures with interpretable electrocardiogram recordings; or 4) use of arrhythmogenic drug. Data acquisition was obtained with a video-EEG monitoring system (Harmonie, Stellate Systems, Canada), which included 32 (scalp) or 64 (intracranial) EEG channels, and one-channel electrocardiogram. Cardiac rhythm recorded 20-30 sec before each seizure onset was compared with cardiac rhythm recorded $10 \mathrm{sec}$ after the onset of seizure. The definition of ictal bradycardia varies in the literature ${ }^{3-5}$. We chose to define absolute IB as a cardiac rhythm less than 60beats per minute (bpm) with a fall of more than $30 \mathrm{bpm}$, severe IB if heart rate (HR) fell below $42 \mathrm{bpm}$ and relative IB as less striking decreases of HR (exceeding $10 \mathrm{bpm}$ ) and HR below $80 \mathrm{bpm}$. In patients with IB, seizure onset, propagation and temporal relation between seizure and bradycardia were determined.

\section{Results}

We analysed a total of 1277 seizures in 69 individuals (34 women, 35 men; mean 36-years-old). Localisation of epileptic focus was frontal in 32\% of all cases ( $n=22 ; 9$ left, 13 right), temporal in $52 \%(n=36 ; 22$ left, 14 right), insular in $4 \%(n=3 ; 1$ left, 2 right), parieto-occipital in $10 \%(\mathrm{n}=7 ; 3$ left, 4 right) and hypothalamic in one case $(1.4 \%)$. Seventeen individuals $(25 \%)$ had intracranial electrodes. The mean number of seizure per individual was 18.5 (3-88 seizures/patient, median of 11). The majority of individuals $(76 \%)$ exhibited ictal tachycardia (data not shown), whereas five individuals (7.2\%) presented absolute
IB and three of them (4\% of all individuals) severe IB (Table). In those five individuals, IB occurred in 24 of their 137 total seizures $(5.7 \%)$. Among these cases, three individuals had a left epileptic focus, and two a right one. Interestingly, in four of the five individuals with absolute IB, we observed a high proportion of seizures associated with relative IB, while a minority of seizures was associated with more severe bradycardia. Four additional individuals (Table) experienced relative IB, but without absolute IB events. Overall, in our cohort, the prevalence of absolute IB in all seizure was $1.9 \%$, and relative IB $8 \%$ and in all individuals, relative and absolute IB survened in $13 \%$ of all individuals.

Individual 2 was diagnosed with ictal asystole associated with atonic seizures (see video in on-line Journal). Severe atonic seizures disappeared after the installation of a PM, although nocturnal tonic clonic and complex partial seizures remained. Subsequent intracranial EEG monitoring revealed a left orbitofrontal epileptic focus. Interestingly, in three spontaneous secondary generalized seizures, bradycardia triggered the pacemaker after diffusion of rhythmic activity from the left orbitofrontal region to the right homologous region. In turn, cortical stimulation of the right rectus gyrus induced two clinical seizures associated with bradycardia, with the pacemaker triggering immediately after diffusion of rhythmic activity from right orbitofrontal region to the left homologous region (Figure). Resection of the left gyrus rectus was performed in this individual who now only presents rare seizures after a follow-up of more than five years.

\section{DISCUSSION}

Although the definition of IB varies in different studies, previous retrospective studies reported a low incidence (1.4\% to $7 \%)^{3-5}$. In contrast, a recent prospective study, monitoring individuals with an implantable loop electrocardiogram recorder 


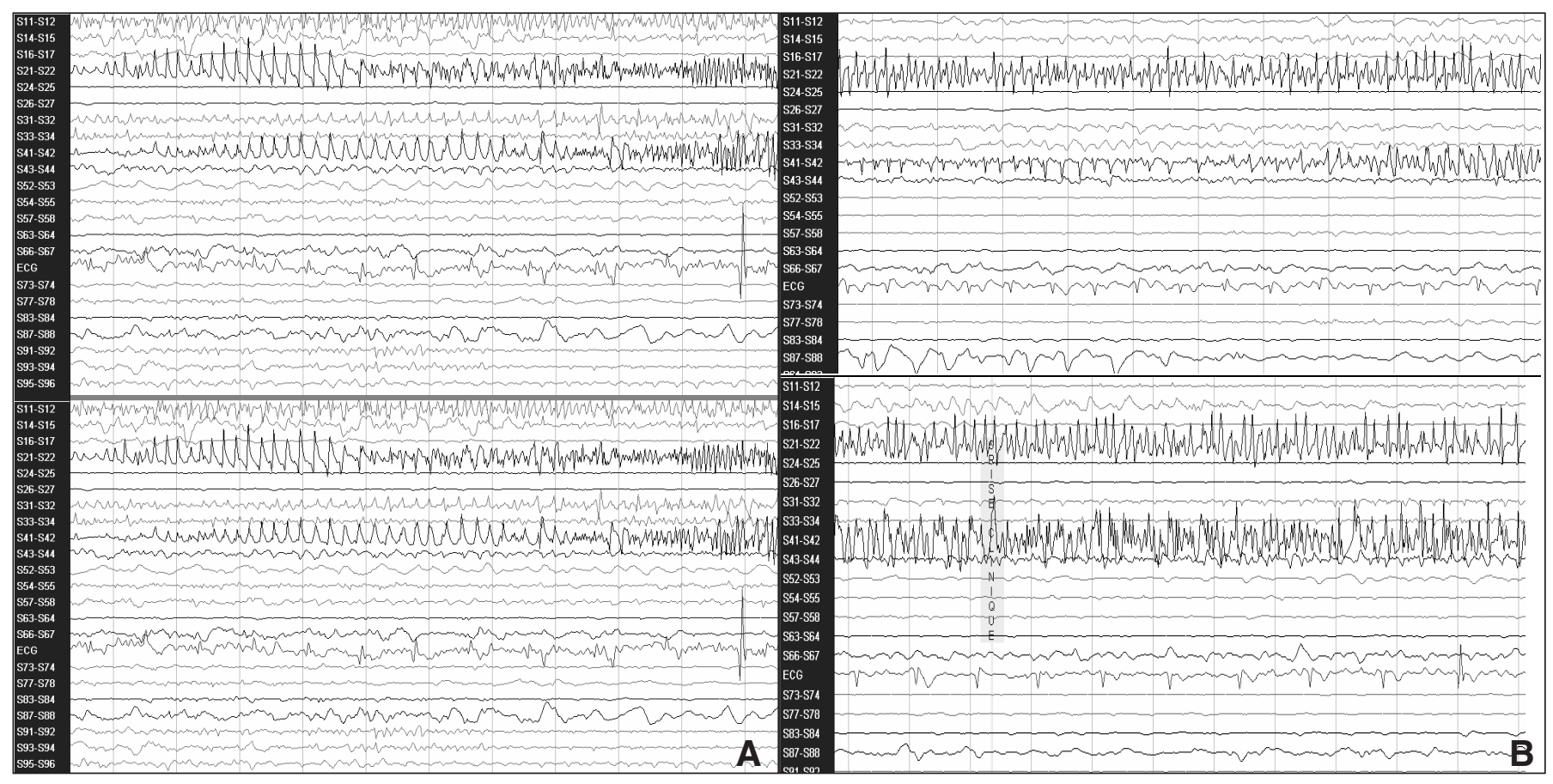

Figure: Invasive EEG recording: A. Spontaneous seizure (left frontal lobe). Pacemaker triggers spontaneously (arrowhead) after diffusion of epileptic activity to the homologous right frontal region. Legend: Orbitofrontal cortex: S11: left, S21: right Rectus gyrus cortex: S31: left, S41: right Sensibility: $100 \mu \mathrm{V}$, except ECG $25 \mu \mathrm{V}$. Each vertical line represents 1 second; B. Forty-three seconds after stimulation of the right rectus gyrus cortex, provoking a right frontal lobe seizure. Pacemaker triggers spontaneously (arrowhead) after diffusion of epileptic activity to the homologous left frontal region. Legend: Sensibility: $100 \mu \mathrm{V}$, except ECG $50 \mu \mathrm{V}$.

for a long period of time, found a much higher incidence of potentially life-threatening IB, including ictal asystole in up to $15.7 \%$ of these individuals ${ }^{3}$. This apparent discrepancy is most likely explained by the methods of detection. Based on these results, the authors stressed the importance of prolonged recordings. This observation sheds important light on the potential detection of life-threatening ictal events. However, the use of an implantable loop electrocardiogram recorder is an expensive and invasive procedure. We believe that the identification of additional criteria for high risk individuals would be very helpful in order to select which individuals may benefit from prolonged electrocardiogram monitoring.

Consistent with previous retrospective studies, we have found a low incidence $(1.9 \%)$ of absolute IB. However, as previously reported $^{4,5}$, we found that the temporal relation between HR change and epileptic activity was usually similar for a given individual. In particular, with respect to IB, we observed that in the majority of individuals with absolute IB $(n=4)$, relative IB was also detected in more than $50 \%$ of their seizures. Based on this observation, we hypothesize that epileptic individuals presenting some minor IB could be more at risk for lifethreatening IB. We have also detected relative IB in four additional individuals, who did not exhibit absolute IB. Should the individuals with either relative or absolute IB exhibit higher risk of severe IB, the proportion of individuals at risk in our cohort would reach $13 \%$, a proportion similar that the one reported by Rugg-Gunn ${ }^{3}$.

Ictal cardiac dysrhythmia is believed to implicate diffusion of epileptic discharges to brain structures involved in central autonomic system control ${ }^{2}$. Based on brain stimulation ${ }^{6}$ and electroconvulsive therapy, the left hemisphere would modulate the parasympathetic tone, whereas the right hemisphere modulates the sympathetic tone. There was no clear association with lateralisation or localisation of the epileptic focus in our cohort. Although this observation is limited by the small number of individuals in our cohort exhibiting IB, this observation is consistent with previous small series ${ }^{7}$.

Among individuals with ictal asystole reported in the literature, five (including the individual reported in our study) had bilateral intracranial recordings ${ }^{8-11}$. The localisation of the epileptic focus was respectively temporal (left in two, not specified in one), left orbito-frontal, and right frontoneotemporal. Interestingly, in four of these cases, the onset of asystole was associated with diffusion of the epileptic discharges in the contralateral homologous regions ${ }^{8-10}$. Asystole may thus result from a particular propagation pattern implicating subcortical autonomic structures. Alternatively, propagation to both orbitofrontal, temporal or insular cortices may be responsible for asystole. The disappearance of severe atonic seizures in individual 2 after the installation of PM suggests that 
ictal atonia may be explained in some seizures by asystole rather than by the epileptic activity itself, as reported by others ${ }^{12}$.

We have found that $4 \%$ of individuals from our cohort exhibit severe ictal bradycardia. Although these events represent a small fraction of all their seizures, these individuals exhibit also relative ictal bradycardia, which may represent a risk factor for the development of life-threatening ictal bradycardia. We suggest that these potentially high-risk individuals may benefit from prolonged implantable electrocardiogram monitoring.

\section{ACKNOWLEDGMENTS}

The authors thank Hélène Cossette, Suzanne Lebrun, Nancy Lévesque, Julie Forand and Gontran Imbeault, electrophysiology technologists, for their assistance in data acquisition and preparation of the figures. Patrick Cossette is supported by the Canadian Institutes for Health Research (CIHR). Dang Khoa Nguyen is the recipient of a Clinical Research Scholar Bursary from the CHUM Research Centre.

We confirm that we have read the Journal's position on issues involved in ethical publication and affirm that this report is consistent with those guidelines. The authors report no conflicts of interest.

\section{REFERENCES}

1. Nashef L, Fish DR, Sander JW, Shorvon SD. Incidence of sudden unexpected death in an adult outpatient cohort with epilepsy at a tertiary referral center. J Neurol Neurosurg Psychiatry. 1995;58:462-4.

2. Devinsky O. Effects of seizure on autonomic and cardiovascular function. Epilepsy Curr. 2004;4:43-6.

3. Rugg-Gunn FJ, Simister RJ, Squirell M, Holdright DR, Duncan JS. Cardiac arrhythmias in focal epilepsy: a prospective long-term study. Lancet. 2004;364:2212-9.

4. Leutmezer F, Schernthaner C, Lurger S, Pötzelberger K, Baumgartner C. Electrocardiographic changes at the onset of epileptic seizures. Epilepsia. 2003;44:348-54.

5. Zijlmans M, Flanagan D, Gotman J. Heart rate changes and ECG abnormalities during epileptic seizures: prevalence and definition of an objective clinical sign. Epilepsia. 2002;43: 847-54.

6. Oppenheimer S, Gelb A, Girvin J, Hachinsky VC. Cardiovascular effects of human insular cortex stimulation. Neurology. 1992;42: 1727-32.

7. Tinuper P, Bisulli F, Cerullo A, Carcabgiu R, Marini C, Pierangeli $\mathrm{G}$, et al. Ictal bradycardia in partial epileptic seizures. Brain. 2001;124:2361-71.

8. Rosetti AO, Dwoetzky BA, Madsen JR, Golub O, Beckman JA, Bromfield EB. Ictal asystole with convulsive syncope mimicking secondary generalisation: a depth electrode study. J Neurol Neurosurg Psychiatry. 2005;75:885-7.

9. Devinsky O, Steven P, Tatambhotla G. Bradycardia and asystole induced by partial seizures: a case report and literature review. Neurology. 1997;48:1712-4.

10. Ghearing GR, Britton JW. The ictal bradycardia syndrome: clinical features, localization and results of cardiac pacing. Neurology. 2004;62 Suppl 5:A250. Abstract.

11. Kahane P, Di Leo M, Hoffman D, Munari C. Ictal bradycardia in a patient with a hypothalamic hamartoma: a stereo-EEG Study. Epilepsia. 1999;40:522-7.

12. Schuele SU, Bermeo AC, Alexopoulos AV. Video-electrographic and clinical features in patients with ictal asystole. Neurology. 2007;69:434-41. 